\title{
Self-Sensing Carbon Based Cement Composite Material
}

\author{
Sardar Kashif Ur Rehman ${ }^{1, *}$, Zainah Ibrahim ${ }^{1}$, Mohammad Faisal Javed ${ }^{1}$, Mohammad Usman Hanif ${ }^{1}$, \\ Khalid Ghaedi ${ }^{1}$
}

\begin{abstract}
Cement-based composite sensors provide a great platform for structural health monitoring (SHM). These composite sensors possess piezo-resistive characteristics which make them very suitable for sensing the stress/strain. In this study, carbon materials i.e. graphene nanoplatelets (GNPs) and single walled carbon nanotubes (SWCNTs) were incorporated into cementitious material. Electrical resistivity values were decreased $17 \%$ and $42 \%$ for SWCNTs and GNP cement composite respectively. It was found that carbon based cement composite was having overall more sensitivity to electrical resistivity values by increasing compressive load. Hence, these nanomaterials based cement composite samples can be used as sensor for self-sensing purposes.
\end{abstract}

Keywords-Cement-based composite; Sensor; Piezo-resistivity; Graphene nanoplatelets; Carbon nanotubes.

\section{INTRODUCTION}

Civil Infrastructures begin to deteriorate due to external conditions. Keeping them in safe and reliable condition is one of the big challenge for engineers. Non-destructive test offers skills for speedily and effectively monitoring these structures [1]. However, self-sensing concrete, which can monitor its own strain, is gaining interest throughout the scientific community. If cement is reinforced with conducting fillers i.e. carbon materials, then it can observe its own strain by monitoring electrical resistivity values [2]. These nanocarbons are capable of fabricating new kind of highly-performance tailored multifunctional cement-based composite that is able of self-sensing its real-time damage [3-6]. Carbon nanotubes (CNTs) are composed of $\mathrm{sp}^{2}$ hybridized carbon atoms, sheets of single layered graphene sheet rolled up in a cylindrical tube [7]. CNTs can be further classified into multi-walled carbon nanotubes (MWCNTs) and single-walled carbon nanotubes (SWCNTs) depending upon the total number of tubes in the concentric arrangement [7]. In fact, SWCNTs can be either semiconductors or metals depending upon their arrangement of the microscopic atoms. Comparatively, only a few researches had been conducted on cement based composite with SWCNTs but huge researches had been conducted on cement composites with MWCNTs. Saafi [8] conducted a study on the piezo-resistivity properties and electrical resistance of different contents of SWCNTs being incorporated into the cementitious material. The results revealed a sudden reduction in the electrical resistance when the content of SWCNTs was being

\footnotetext{
${ }^{1}$ Department of Civil Engineering, University of Malaya 50603, Kuala Lumpur, Malaysia

* Corresponding authors; E-mail: kashif@engineersdaily.com.
}

increased from zero to $1.5 \%$ by volume. If these rolled sheets of CNTs are opened up in one plane, then it forms the twodimensional sheet like structure. These two-dimensional sheets i.e. graphene nanoplatelets (GNPs) have even greater surface area and aspect ratio. Du et al. [10] studied the effect of different concentration of GNPs on the sensing behaviour of the cementitious composite and compared it with normal cementitious material. They found that by using $2.4 \%$ to $3.6 \%$ of GNPs by volume of cement revealed a decrement in the electrical resistivity. As the content of GNPs increases, the fractional change in electrical resistance becomes larger which means increased piezo-resistivity for the similar strain. The electrical resistance sensitivity to strain is nearly undetectable for GNP content that is below the value of $2.4 \%$ by volume of cement [10]. Therefore, in this study, we used very small amount $(0.03 \%)$ by weight of cement of carbon materials as compared with existing research to determine the self-sensing properties of the cementitious material. Fractional change in resistance was observed and used for determining self-sensing characteristics.

\section{II.EXPERIMENTAL METHODOLOGY}

\section{A. Materials}

In this experimental work the consumed materials were cement, fine aggregates, CNT, GNP and superplasticizer. The cement being used was the Type I Ordinary Portland Cement (Tasek Corporation Berhad), which was the CEM I $42.5 \mathrm{~N}$ based on MS EN 197-1. The number 42.5 refers to standard strength class of 42.5 , the prefix $\mathrm{N}$ refers to normal early strength and the prefix I refers to type I Ordinary Portland Cement (OPC). For the fine aggregates, sand of $2 \mathrm{~mm}$ maximum size was being used with fineness modulus of 2.9. Sika ViscoCrete 2055 (Sika Kimia Sdn. Bhd.), a thirdgeneration high range water reducing polycarboxylate ether based superplasticizer was being used. Meanwhile, the carbon materials i.e. SWCNTs and GNP were used. The short SWCNT was purchased from Nanostructured \& Amorphous Materials, Inc. and GNP was produced from grade AO-3 GNP Graphene Laboratories, Inc. The properties of both the SWCNT and GNP are given in Table 1 and Table 2 respectively. 
TABLE I

THE PROPERTIES OF SWCNTS USED FOR THIS EXPERIMENT.

\begin{tabular}{ll}
\hline Diameter from HRTEM $(\mathrm{nm})$ & $1.0-2.0$ \\
Diameter from Raman spectra $(\mathrm{nm})$ & $0.8-1.6$ \\
$\begin{array}{l}\text { Average diameter from Raman spectra } \\
(\mathrm{nm})\end{array}$ & 1.1 \\
Length $(\mu \mathrm{m})$ & $1.0-3.0$ \\
Specific surface $\mathrm{area}^{3}, \mathrm{SSA}\left(\mathrm{m}^{2} / \mathrm{g}\right)$ & $360-400$ \\
Bulk density $\left(\mathrm{g} / \mathrm{cm}^{3}\right)$ & $0.22-0.27$ \\
Purity & $90 \%$ CNTs and $60 \%$ \\
& SWCNTs \\
Color & Black \\
\hline
\end{tabular}

TABLE II

THE PROPERTIES OF GNPS USED FOR THIS EXPERIMENT

Average flake thickness (nm) $12(30-50$ monolayers)

Average particle (lateral) size $~ 4500(1500-10000$

(nm)

$\mathrm{nm})$

Specific surface area, SSA $\left(\mathrm{m}^{2} / \mathrm{g}\right) \quad 360-400$

Purity $99.2 \%$

Color Black

\section{B. Preparation of samples:}

For the preparation of specimens, 3 batches of cement paste with a water-cement ratio of 0.4 and nanomaterials to cement ratio was $0.03 \%$ were used. One batch was labelled as control sample containing pure cement paste, while other two batches contained SWCNTs and GNP separately. Firstly, carbon materials were dispersed in deionized water. Ultrasonication (Fisher Scientific ${ }^{\mathrm{TM}}$ Model 505 Sonic Dismembrator) was used for $3 \mathrm{~min}$, in order to exfoliate nanoparticles. The energy that had been introduced into the SWCNT and GNP particles respectively leads to the wreckage of the interlayer $\pi$-bonds. Finally, cement was added to this this aqueous solution of carbon materials and mixed thoroughly for $10 \mathrm{~min}$ in spar mixer (SP-800A). Later on, cement paste was poured into the prism of the dimension 160 x 40 x $40 \mathrm{~mm}$. After that stainlesssteel wire mesh $11 \times 11 \mathrm{~mm}$ with an average thickness of 1.3 $\mathrm{mm}$ was being cut into dimensions of $40 \times 70 \mathrm{~mm}$. The placement of this stainless-steel wire mesh in specimen is given in Figure 1 (b). The outer two wire mesh were positioned at $10 \mathrm{~mm}$ from the ends of the prism and the inner two wire mesh are positioned at $40 \mathrm{~mm}$ from the outer wire mesh and having a length of $60 \mathrm{~mm}$ between them.

\section{Test setup for electrical properties}

Four-probe method was used to determine the piezoresistive properties of the specimens. This method uses the outer two wire mesh to determine the current and inner two wire mesh for the voltage. Experimental investigations were started at the age of 28-days. The setup involves Instron 600 $\mathrm{kN}$ machine used for applying compressive load, TDS-530 data logger to measure the voltage measurements, DC power supply and 10-ohm resistance. Specimens were placed in Instron machine and constant voltage of $15 \mathrm{~V}$ through DC power supply was applied to the samples. 10-ohm resistance was added in series to the electric circuit and voltage drop was measured across it to determine the electric current in the circuit. TDS-530 data logger was being used to provide measurement of the voltage values. Then, inner wire meshes were being connected to the first channel of the data logger and measures the voltage in V. Meanwhile, one of the outer wire meshes was being connected to the negative terminal of the power supply and another outer wire mesh to the resistor followed by the connection to the second channel of the data logger and positive terminal of the power supply forming a series circuit. Schematic illustration is given in Figure 1 (a).

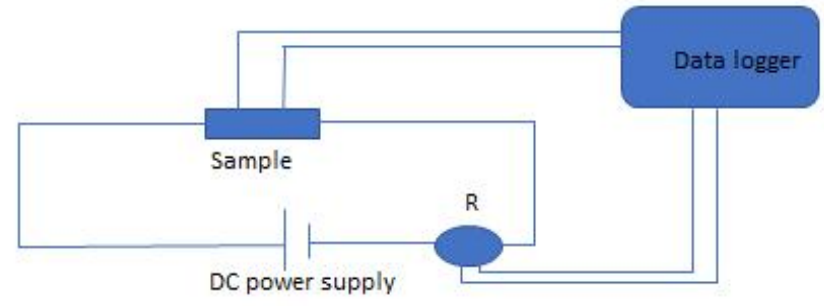

(a)

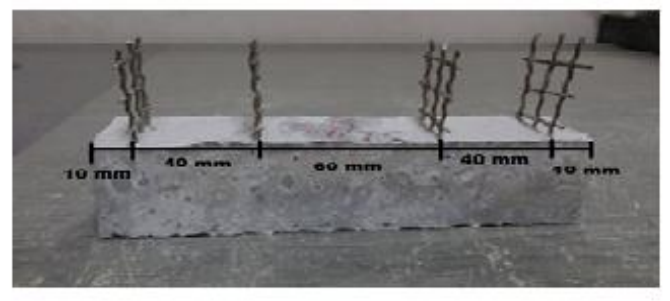

(b)

Fig 1: a) schematic illustration of electric setup b) the positioned of the wire mesh in the prism-shaped specimen.

\section{RESULTS AND DISCUSSIONS}

In this study, DC circuit was being used to calculate the electrical resistance of specimens. Table 3 summarize the experimental readings for the all specimens. It can be seen that by addition of the carbon materials enhanced significantly maximum compressive load of cement paste samples. Electrical resistivity values were reduced by $17 \%$ and $42 \%$ for SWCNTs and GNP cement paste samples respectively. Reduction in electrical resistivity values make them selfsensing material.
TABLE III

MAXIMUM COMPRESSIVE LOAD AND CORRESPONDING RESISTIVITY VALUES

\begin{tabular}{lcc}
\hline Specimen & $\begin{array}{c}\text { Maximum } \\
\text { compressive load } \\
(\mathrm{kN})\end{array}$ & $\begin{array}{c}\text { Four probe resistivity at } \\
\text { maximum compressive } \\
\text { loading }(\mathrm{k} \Omega-\mathrm{cm})\end{array}$ \\
\hline Control & 60.7510 & 59.16 \\
SWCNTs-cement paste & 87.9102 & 48.95 \\
GNP-cement paste & 80.0753 & 34.42 \\
\hline
\end{tabular}

To observe the sensing ability of the specimens normalized compressive loading (NCL) values were calculated. It is the ratio between the applied load to the max compressive load before specimen failure. For electrical resistance values, fractional change in resistance (FCR) was used. The reason for using these two values was doing comparison of the complex 
calculated self-sensing values with an ease and in convenient way. Equation 1 and 2 represents the calculation procedure for the NCL and FCR values.

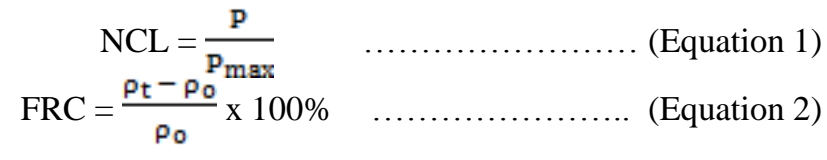

Where:

$\rho_{\mathrm{t}}=$ electrical resistance at the given time during the test; $\rho_{\mathrm{o}}=$ electrical resistance at the start of the test; $\mathrm{P}=$ compressive loading at the given time during the test; $\mathrm{P}_{\max }=$ maximum compressive loading for the specimen.

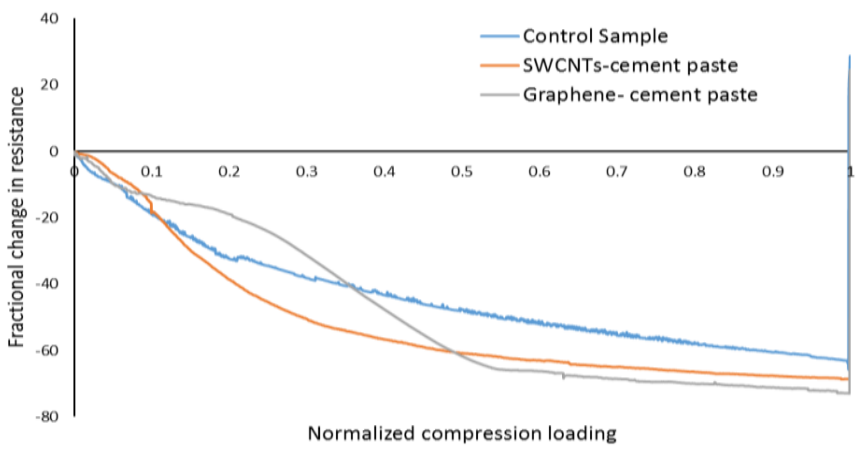

Fig. 2: Fractional change in resistance against normalized compression load

Figure 2 represents the fraction change in resistance values verses the normalized compression load. It was observed that samples containing carbon materials have more fractional change in resistance values as compared with the control sample. By increasing the NCL values or compressive loading the electrical resistance was decreasing. The curve for control sample was steep initially up till $20 \%$ of maximum load and then it became linear. Hence, it cannot predict the occurrence of cracks accurately as up till $20 \%$ very minute hairline cracks initiate and once these cracks were propagating then control sample was not sensing them with accuracy. The curve for the SWCNTs-cement paste sample shows very rapid response from 10-60 \% of applied maximum load and then its response become linear. However, in case of Graphene-cement paste more steep and sharp decrease in electrical resistance values from $20-60 \%$ of maximum load and then it became linear as well. This conclude that up till $60-70 \%$ of maximum load these sensors can sense very accurately. Further research is need by using tensile loading which will give more better understanding about strain sensing capabilities of these sensors.

\section{CONCLUSIONS}

In this study, piezo-resistive properties of carbon materials i.e. SWCNTs and GNP based cementitious composite were investigated. Electrical resistivity values were decreased $17 \%$ and $42 \%$ for SWCNTs and GNP cement composite respectively. It was also observed that overall electrical resistance values were decreased with increasing the compressive load, especially from $10-70 \%$ of applied maximum compressive load very steep and rapid decrement was noted. Therefore, these carbon based cement composites can act as self-sensing materials and can determine the propagation of cracks in a more better way.

\section{ACKNOWLEDGEMENT}

This research was supported by University Malaya Research Grant (UMRG - Project No. RP004A/13AET), University Malaya Postgraduate Research Fund (PPP - Project No. PG217-2014B) and Fundamental Research Grant Scheme, Ministry of Education, Malaysia (FRGS - Project No. FP028/2013A).

\section{REFERENCES}

[1]Rehman SKU, Ibrahim Z, Memon SA, Jameel M. 2016. Nondestructive test methods for concrete bridges: A review. Construction and Building Materials;107:58-86 https://doi.org/10.1016/j.conbuildmat.2015.12.011

[2] Chung D. 2002. Piezoresistive cement-based materials for strain sensing. Journal of Intelligent Material Systems and Structures;13(9):599-609 https://doi.org/10.1106/104538902031861

[3] Sanchez F, Sobolev K. 2010. Nanotechnology in concrete-a review. Construction and Building Materials;24(11):2060-71. https://doi.org/10.1016/j.conbuildmat.2010.03.014

[4] Raki L, Beaudoin J, Alizadeh R, Makar J, Sato T. 2010. Cement and concrete nanoscience and nanotechnology. Materials;3:918-42 https://doi.org/10.3390/ma3020918

[5] Sobolev K, Gutiérrez MF. 2005. How nanotechnology can change the concrete world. American Ceramic Society Bulletin;84(10):14.

[6] Mukhopadhyay AK. Next-generation nano-based concrete construction products: a review. Nanotechnology in Civil Infrastructure: Springer; 2011. p. 207-23 https://doi.org/10.1007/978-3-642-16657-0_7

[7] Vajtai R. Springer handbook of nanomaterials: Springer Science \& Business Media; 2013. https://doi.org/10.1007/978-3-642-20595-8

[8] Saafi M. 2009. Wireless and embedded carbon nanotube networks for damage detection in concrete structures. Nanotechnology;20(39):395502. https://doi.org/10.1088/0957-4484/20/39/395502

[9] Li GY, Wang PM, Zhao X. 2005. Mechanical behavior and microstructure of cement composites incorporating surface-treated multi-walled carbon nanotubes. Carbon;43(6):1239-45. https://doi.org/10.1016/j.carbon.2004.12.017

[10] Du H, Quek ST, Dai Pang S. Smart multifunctional cement mortar containing graphite nanoplatelet. SPIE Smart Structures and Materials+ Nondestructive Evaluation and Health Monitoring: International Society for Optics and Photonics; 2013. p. 869238-10 